\title{
Cardiac magnetic resonance differences in ventricular function and delayed enhancement according to clinical presentation in Chagas disease
}

\author{
Luis E Rodriguez Castellanos*, Gabriela Melendez, Aloha Meave, Jorge I Magaña, Leyli C Velasquez Alvarez \\ From 18th Annual SCMR Scientific Sessions \\ Nice, France. 4-7 February 2015
}

\section{Background}

Chagas disease is a parasitosis caused by the protozoan Trypanosoma cruzi. It is endemic in Latin America, nevertheless it has spread to other regions of the world due to migration. Up to $30 \%$ of the infected patients progress to the chronic phase, with a 5 -year mortality of $50 \%$ due to heart failure or ventricular arrhythmias. We aimed to compare ventricular function and delayed enhancement (DE) according to the predominant clinical presentation in Chronic Chagas disease (CCD) either ventricular tachycardia (VT) or heart failure (HF), as well as to compare CCD with the undetermined and subclinical phases.

\section{Methods}

Fifty-one patients with serologic diagnosis of Chagas disease underwent cardiac magnetic resonance (CMR) from 2009 to 2014 at our institution. Patients were classified as undetermined, subclinical and CCD, according to clinical, EKG and echocardiographic findings. CCD patients were further subdivided according to the predominant clinical presentation into those with VT or HF.

\section{Results}

Out of 51 patients, 6 were classified as undetermined, 5 subclinical and 40 with CCD (21 VT and $19 \mathrm{HF}$ ). Myocardial scar expressed as mass and percentage of myocardium was similar between patients with VT and those with HF $(44.5 \pm 20.1$ g. vs. $48.6 \pm 30.5$ g. $\mathrm{p}=0.62$ and $43.8 \pm 13 \%$ vs. $46.4 \pm 19.9 \%, \mathrm{p}=0.64$ respectively). There was significant difference in DE distribution, basal lateral wall (both anterolateral and inferolateral) was affected in $91 \%$ of patients with VT compared to $55 \%$ of those with HF, $\mathrm{p}=0.02$. Patients with VT had higher left ventricular ejection fraction than patients with HF $(36.3 \pm 10.9 \%$ vs. $23.5 \pm$ $10.6 \%, \mathrm{p}<0.001$ ) and lower end-systolic volume $[99 \mathrm{ml}$ (IQR 75-158) vs $153 \mathrm{ml},(82-193) ; \mathrm{p}=0.02]$. Compared with HF patients those with VT had higher right ventricular ejection fraction [43\% (31-49) vs $26 \%(18-45) ; \mathrm{p}=0.03$ ] and lower right end-diastolic and end-systolic volumes [68 $\mathrm{ml}$ (58-96) vs $100 \mathrm{ml}$ (71-171), $\mathrm{p}=0.01$ and $36 \mathrm{ml}(32-67)$ vs $68 \mathrm{ml} \mathrm{I}(42-129), \mathrm{p}=0.004$ respectively].

\section{Conclusions}

There was no significant difference in DE burden between patients with VT or HF in CCD; however the DE distribution was significantly different, with the lateral wall more frequently involved in VT group. HF patients had biventricular lower ejection fraction with higher end-systolic and end-diastolic volumes.

\section{Funding}

None.

Published: 3 February 2015

doi:10.1186/1532-429X-17-S1-P270

Cite this article as: Rodriguez Castellanos et al: Cardiac magnetic resonance differences in ventricular function and delayed enhancement according to clinical presentation in Chagas disease. Journal of Cardiovascular Magnetic Resonance 2015 17(Suppl 1):P270. 


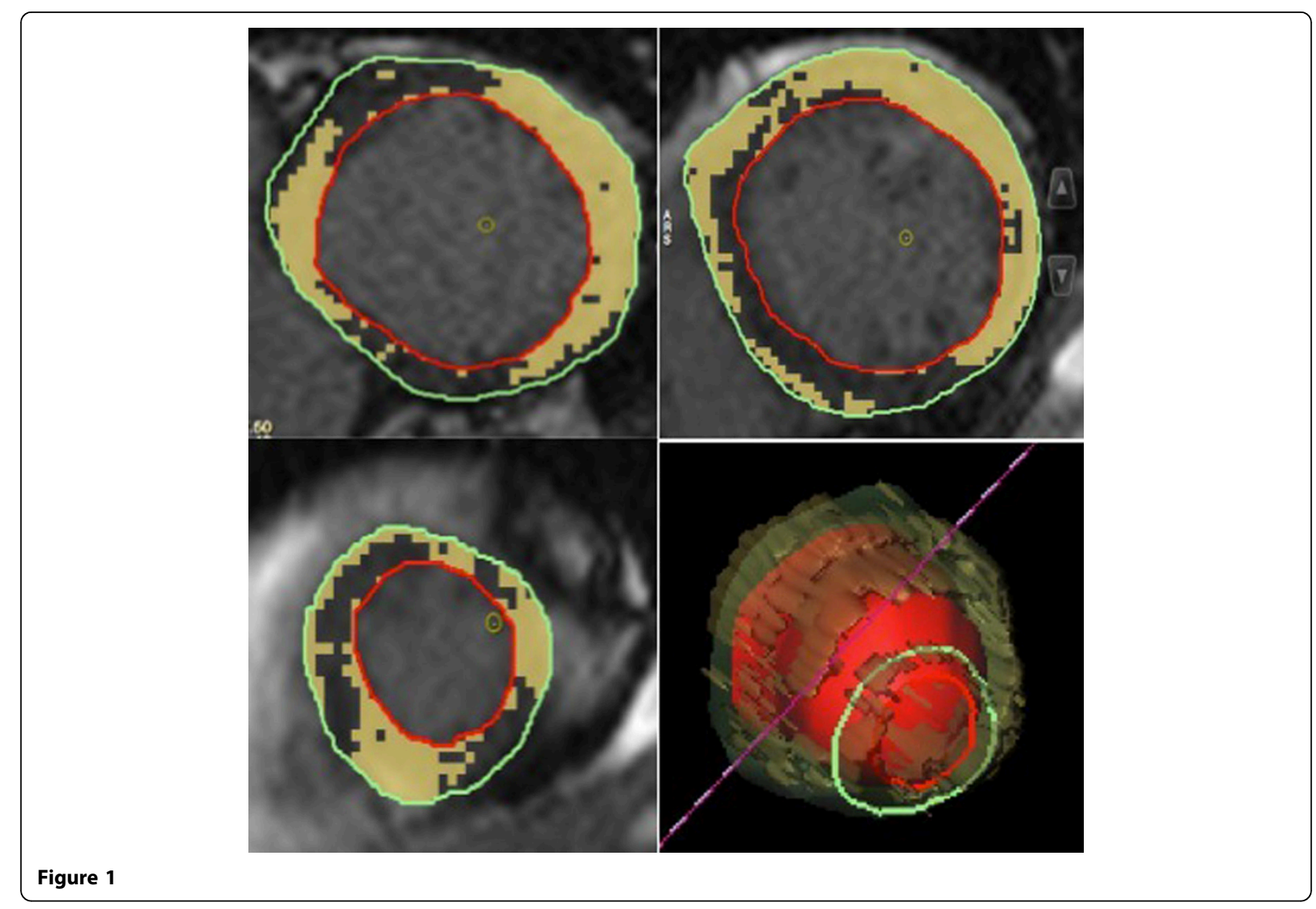

Table 1 Differences according predominant to clinical presentation in Chronic Chagas Disease.

\begin{tabular}{|c|c|c|c|}
\hline & With VT $(n=21)$ & Witout VT $(n=19)$ & $p$ \\
\hline Male sex, $\mathrm{n}(\%)$ & $14(66)$ & $8(42)$ & 0.20 \\
\hline Age (years) & $58.5 \pm 12.7$ & $55.6 \pm 13.4$ & 0.48 \\
\hline EDLVD $(\mathrm{mm})$ & $57(54-76)$ & $63(57-69)$ & 0.08 \\
\hline ESLVD $(\mathrm{mm})$ & $46(40-61)$ & $54(48-64)$ & 0.14 \\
\hline $\operatorname{LVEF}(\%)$ & $36.3 \pm 10.9$ & $23.5 \pm 10.6$ & $<0.001$ \\
\hline LVEDV $(\mathrm{ml})$ & $165(148-221)$ & $191(132-230)$ & 0.16 \\
\hline LVESV (ml) & $99(75-158)$ & $153(82-193)$ & 0.02 \\
\hline Left Ventricular Mass (g) & $88(85-114)$ & $106(87-144)$ & 0.13 \\
\hline RVEF (\%) & $43(31-49)$ & $26(18-45)$ & 0.03 \\
\hline RVEDV (ml) & $68(58-96)$ & $100(71-171)$ & 0.01 \\
\hline RVESV (ml) & $36(32-67)$ & $68(42-129)$ & 0.004 \\
\hline Ventricular Aneurism n(\%) & $6(28)$ & $3(16)$ & 0.46 \\
\hline Thrombus & $1(5)$ & $6(32)$ & 0.04 \\
\hline Left Anterior Fascicular Block n(\%) & $1(4)$ & $3(16)$ & 0.33 \\
\hline Segments with delayed enhacement & $8.9 \pm 3.0$ & $9.3 \pm 3.6$ & 0.69 \\
\hline Fibrosis grade (Cuantitative Delayed Enhacement) (gr) & $44.5 \pm 20.2$ & $48.6 \pm 30.5$ & 0.62 \\
\hline Percentage of fibrosis (delayed enhacement \%) & $43.8 \pm 13.0$ & $46.4 \pm 19.9$ & 0.64 \\
\hline
\end{tabular}

